\title{
BMJ Open Are lower levels of red blood cell transfusion more cost-effective than liberal levels after cardiac surgery? Findings from the TITRe2 randomised controlled trial
}

\author{
E A Stokes, ${ }^{1}$ S Wordsworth, ${ }^{1}$ D Bargo, ${ }^{1,2} \mathrm{~K}$ Pike, ${ }^{3}$ C A Rogers, ${ }^{3}$ R C M Brierley, ${ }^{3}$ \\ G D Angelini, ${ }^{4} \mathrm{G}$ J Murphy, ${ }^{5} \mathrm{~B} \mathrm{C}$ Reeves, ${ }^{3}$ on behalf of the TITRe2 Investigators
}

To cite: Stokes EA, Wordsworth S, Bargo D, et al. Are lower levels of red blood cell transfusion more cost-effective than liberal levels after cardiac surgery? Findings from the TITRe2 randomised controlled trial. BMJ Open 2016;6:e011311. doi:10.1136/bmjopen-2016011311

- Prepublication history and additional material is available. To view please visit the journal (http://dx.doi.org/ 10.1136/bmjopen-2016011311)

Received 28 January 2016 Revised 27 May 2016 Accepted 30 June 2016

\section{CrossMark}

For numbered affiliations see end of article.

Correspondence to Dr Sarah Wordsworth; sarah.wordsworth@dph.ox. ac.uk

\section{ABSTRACT}

Objective: To assess the incremental cost and costeffectiveness of a restrictive versus a liberal red blood cell transfusion threshold after cardiac surgery.

Design: A within-trial cost-effectiveness analysis with a 3-month time horizon, based on a multicentre superiority randomised controlled trial from the perspective of the National Health Service (NHS) and personal social services in the UK.

Setting: 17 specialist cardiac surgery centres in UK NHS hospitals.

Participants: 2003 patients aged $>16$ years undergoing non-emergency cardiac surgery with a postoperative haemoglobin of $<9 \mathrm{~g} / \mathrm{dL}$.

Interventions: Restrictive (transfuse if haemoglobin $<7.5 \mathrm{~g} / \mathrm{dL}$ ) or liberal (transfuse if haemoglobin $<9 \mathrm{~g} / \mathrm{dL}$ ) threshold during hospitalisation after surgery.

Main outcome measures: Health-related quality of life measured using the EQ-5D-3L to calculate qualityadjusted life years (QALYs).

Results: The total costs from surgery up to 3 months were $£ 17945$ and $£ 18127$ in the restrictive and liberal groups (mean difference is $-£ 182,95 \% \mathrm{Cl}-£ 1108$ to $£ 744$ ). The cost difference was largely attributable to the difference in the cost of red blood cells. Mean QALYs to 3 months were 0.18 in both groups (restrictive minus liberal difference is $0.0004,95 \% \mathrm{Cl}-0.0037$ to $0.0045)$. The point estimate for the base-case costeffectiveness analysis suggested that the restrictive group was slightly more effective and slightly less costly than the liberal group and, therefore, cost-effective. However, there is great uncertainty around these results partly due to the negligible differences in QALYS gained.

Conclusions: We conclude that there is no clear difference in the cost-effectiveness of restrictive and liberal thresholds for red blood cell transfusion after cardiac surgery.

Trial registration number: ISRCTN70923932;

Results.

\section{INTRODUCTION}

Perioperative anaemia is common after cardiac surgery and is associated with adverse

\section{Strengths and limitations of this study}

- The cost-effectiveness analysis was based on data collected for a large randomised controlled trial, the Transfusion Indication Threshold Reduction trial, which randomised four times more participants than the next largest trial comparing restrictive and liberal transfusion thresholds after cardiac surgery.

- Very detailed individual patient cost and quality-of-life data were collected from the trial which achieved a high level of completeness of follow-up.

- Only participants who breached the liberal threshold were randomised; this avoided diluting the treatment effect with similar numbers of participants in each group who were unlikely to be transfused.

- The unit costs of administering red blood cells used in this study captured the nursing costs associated with transfusion, but not other inputs such as those of the transfusion laboratory.

clinical outcomes, such as stroke, acute kidney injury and death. ${ }^{1-3}$ Transfusion of allogeneic red blood cells is a mainstay treatment for acute anaemia and, on average, over $50 \%$ of adult cardiac surgery patients receive a perioperative blood transfusion. ${ }^{4} 5$ Cardiac surgery consumes a substantial proportion of blood supplies; over $6 \%$ of all red blood cell usage in the UK occurs in cardiac surgery. ${ }^{6}$

Red blood cell transfusion is essential in some cardiac surgical patients for the management of life-threatening haemorrhage. In most cases, however, decisions to transfuse are made because the haemoglobin $(\mathrm{Hb})$ concentration has fallen to a level or threshold at which the surgeon or critical care anaesthetist responsible for a patient's care feels uncomfortable. $^{2} 78$ The transfusion 
threshold varies between different cardiac surgery units across the UK and between different doctors, which contributes to the wide variation in blood usage observed in cardiac surgical units $(25-95 \%) .{ }^{4}{ }^{5} 9$ A key reason for the threshold variation is the lack of evidence regarding what constitutes a 'safe' level of anaemia following cardiac surgery.

The Transfusion Indication Threshold Reduction (TITRe2) trial was designed to test the hypothesis that a restrictive threshold for red blood cell transfusion $(\mathrm{Hb}$ $<7.5 \mathrm{~g} / \mathrm{dL}$ ) after cardiac surgery would reduce postoperative morbidity and health service costs compared to a liberal threshold ( $\mathrm{Hb}<9 \mathrm{~g} / \mathrm{dL}$ ). The primary clinical outcome for TITRe 2 was a composite of a serious infectious or ischaemic event within 3 months of randomisation. The trial results reported no difference in the primary clinical outcome between the transfusion groups (the primary outcome was observed in $35.1 \%$ and $33.0 \%$ of participants in the restrictive and liberal groups, respectively). This finding supports the use of either transfusion threshold as evaluated in the trial. This might suggest a restrictive threshold is preferred since this reduces unnecessary transfusions. However, analyses of a secondary outcome, mortality at 90 days, found a borderline significant difference between the groups $(4.2 \%$ of patients in the restrictive group died vs $2.6 \%$ of patients in the liberal group, $\mathrm{p}=0.045$ ) creating uncertainty about recommending restrictive transfusion after cardiac surgery.

Given the pressures on healthcare resources and the costs and scarcity of red blood cells, it is important to consider the cost-effectiveness as well as the clinical effectiveness of alternative transfusion thresholds. We are unaware of any previous trial-based economic evaluation assessing the cost-effectiveness of alternative transfusion thresholds after cardiac surgery. This paper reports the methods and results of the within-trial costeffectiveness analysis for the TITRe2 trial.

\section{METHODS}

Our economic evaluation was based on the TITRe2 trial (ISRCTN70923932) which provided highly detailed data on resource use and health-related quality of life (HRQoL) of participants. The trial methods and results are reported in detail elsewhere, ${ }^{7} 10$ and the trial CONSORT diagram is provided in the online supplementary appendix 1 of this paper. In summary, TITRe2 was a multicentre superiority trial in which patients aged $>16$ years having non-emergency cardiac surgery, whose $\mathrm{Hb}$ dropped to $<9 \mathrm{~g} / \mathrm{dL}$ during the postoperative hospital stay, were randomised to a restrictive threshold (transfuse if $\mathrm{Hb}<7.5 \mathrm{~g} / \mathrm{dL}$ ) or a liberal threshold (transfuse if $\mathrm{Hb}<9 \mathrm{~g} / \mathrm{dL}$ ). Patients were recruited from 17 specialist cardiac surgery centres in UK National Health Service (NHS) hospitals between July 2009 and February 2013.

Our analysis was conducted from an NHS and personal social services perspective, as recommended by the
UK National Institute for Health and Care Excellence. ${ }^{11}$ The economic evaluation comprised a within-trial costeffectiveness analysis, with the main outcome measure being quality-adjusted life years (QALYs), and took a 3-month time horizon, as we anticipated that most major resource use would occur within 3 months of cardiac surgery. Surgery was chosen as the time origin for our analyses (rather than the point of randomisation, as was the case with the analysis of effectiveness), in order to capture the resources that would be required for the intervention from a decision-maker's perspective, that is, to include all relevant costs (and effects) involved in delivering the cardiac surgery.

\section{Resource use and costs}

Resource use data were collected on all significant health service resource inputs for the trial participants up to the point of the 3 month follow-up. During the index hospital admission, data collection was integrated into the trial case report forms; data were collected on blood products transfused, inpatient days by ward type, type of cardiac surgery and reoperations, medications and complications. At 3 months postoperatively, a bespoke resource use questionnaire was used to obtain estimates of healthcare resources used since hospital discharge, for example, readmissions to hospital and further contact with health professionals in primary or secondary care. The costs of unrelated care postdischarge were excluded. For example, our analysis included the cost of readmissions for hypertension and angina, but excluded the cost of readmissions for treatment of cancer.

Unit costs used to value hospital and community healthcare resource use were largely obtained from national sources, for example, NHS Blood and Transplant (NHSBT) price lists for blood products, the National Schedule of Reference Costs for intensive care, high-dependency and cardiac ward costs, MRI and CT scans and many complications, and Unit Costs of Health and Social Care for community costs. ${ }^{12-14}$ All unit costs are provided in the online supplementary appendix 2. Resources were valued in 2012/2013 pounds sterling; any unit costs in pre-2012/2013 prices were inflated to 2012/2013 using the Hospital and Community Health Services inflation index. ${ }^{14}$ Costs of drugs given in hospital were taken from the Electronic Marketing Information Tool where possible, which provides the reduced prices paid for generic drugs in hospital. ${ }^{15}$ Drug costs not available from this source or prescribed in the community were taken from the British National Formulary. ${ }^{16}$

\section{HRQoL and QALYs}

The main outcome measure for the economic evaluation was HRQoL, using QALYs, which were derived from EQ-5D-3L utilities (measured on a continuous scale and time under observation). The EQ-5D was administered to participants preoperatively, and at 
6 weeks and 3 months postoperatively. The analysis of QALYs required baseline utility to be modelled as a covariate; the correlation between baseline and 3-month EQ-5D-3L utilities was assumed to be $\geq 0.3$. Respondents were assigned valuations derived from published UK population tariffs. ${ }^{17}$ The number of QALYs accrued by each participant was calculated assuming that a participant's utility changed linearly between each of the time points. For participants who died during the trial, their utility was assumed to change linearly between the preceding time point and the time of death, and a value of zero was given to participants from time of death onwards.

\section{Statistical methods}

Our base-case analysis included all participants randomised into the trial except those randomised in error and those who withdrew consent for their data to be used, which is consistent with the main effectiveness analyses. Analyses were performed on an intention-to-treat basis. Overall, $2.5 \%$ of resource use data were completely missing, and $10.7 \%$ of EQ-5D scores were missing across the three time points in the trial. Missing resource use and EQ-5D data were imputed by multiple imputation using a series of chained regression equations. ${ }^{18}$ Five values were predicted for each missing data cell, and a method called Rubin's Rule was used to summarise data across the five data sets. ${ }^{19}$ Where resource use data were partially missing, for example, for linked questions where only the first part was answered, mean imputation was used. For example, if a participant reported general practitioner visits, but did not record the number of visits, the mean number of visits from other participants was assigned to participants whose data were missing.

Given that baseline utility directly contributes to QALY calculations, it is important to control for any potential imbalances in baseline utility in the estimation of the mean difference in QALYs between treatment groups, to avoid introducing bias. ${ }^{20}$ QALYs were therefore adjusted for baseline EQ-5D. Costs and effects were not discounted as the time horizon was $<12$ months. The incremental cost-effectiveness ratio (ICER) was derived from the average costs and QALYs gained in each trial group, producing an incremental cost per QALY gained by implementing a restrictive threshold in place of a liberal threshold. Non-parametric bootstrapping of costs and QALYs was then used to quantify the degree of uncertainty around the ICER. A 1000 bootstrap samples were drawn for each of the five imputed data sets. ${ }^{21}$

\section{Presentation of results}

The mean costs and QALYs gained in each trial arm, with SEs and 95\% CIs are presented, as well as the ICER. Uncertainty around the ICER is represented graphically on the cost-effectiveness plane by the bootstrap replicates of the mean difference in costs and QALYs between the groups. The restrictive threshold would be considered cost-effective if the ICER falls below $£ 20000$ per QALY, the level below which the National Institute for Health and Care Excellence generally recommends interventions to the NHS; however, the ICERs presented allow decision-makers to assess costeffectiveness at a willingness-to-pay threshold of their choice.

\section{Sensitivity analyses}

Deterministic sensitivity analyses were used to investigate the impact on the results of the cost and costeffectiveness analyses when varying key parameters one at a time, or major cost drivers, such as treating costly complications, and also to investigate the impact of uncertainty on the cost-effectiveness results. In terms of costs, key unit costs were varied, the costing was undertaken from the point of randomisation rather than the point of surgery, and the impact of high-cost participants (outliers) were investigated. In terms of outcomes, assumptions for calculating QALYs were varied, and lifeyears gained was considered as an alternative outcome measure to QALYs.

\section{Subgroup analyses}

Clinical opinion suggests that transfusion decisions should be influenced by patients' characteristics, and that 'at-risk' patients should be transfused at a different threshold. Subgroup analyses were conducted to investigate whether cost-effectiveness results varied between the prespecified participant subgroups used for the effectiveness analyses:

- Operation type (isolated coronary artery bypass grafting (CABG) vs other operation types);

- Age at operation ( $<75$ vs $\geq 75$ years);

- Preoperative diagnosis of diabetes (none vs diet, oral medication or insulin controlled);

- Preoperative diagnosis of lung disease (none vs chronic pulmonary disease or asthma);

- Preoperative renal impairment (estimated glomerular filtration rate $\leq 60 \mathrm{~mL} / \mathrm{min}$ vs estimated glomerular filtration rate $>60 \mathrm{~mL} / \mathrm{min}$ );

- Sex (males vs females);

- Preoperative ventricular function (good vs moderate or poor).

The impact of subgroups was evaluated using ordinary least squares regression separately for total costs and for QALYs, conditional on treatment group, subgroup and an interaction between treatment group and subgroup, (and baseline EQ-5D for QALYs only).

\section{RESULTS}

The trial randomised a total of 2007 participants; four withdrew, leaving an analysis population consisting of 2003 participants, 1000 in the restrictive group and 1003 in the liberal group. Participants had a mean age of 69 years, and $69 \%$ were men. Most participants underwent coronary artery bypass grafting $(40.7 \%)$ or valve surgery $(30.5 \%) .{ }^{10}$ 


\section{Resource use and costs}

There was little difference in resource use between the groups (table 1). Red blood cells were the only resource item for which there was a clear difference, an expected finding given that the liberal group by definition had more red blood cells transfused (mean difference 1.00 (SE 0.14) unit per participant). A detailed list of all the unit cost values attached to these resources is provided in the online supplementary appendix 2 .

A breakdown of total costs of care from surgery to 3 months is shown in table 2. Key drivers of total costs were surgery, complications and length of stay (LOS). The difference in the mean units of red blood cells transfused translated into a statistically significant average difference in red blood cell costs (£140, SE 19, $\mathrm{p}<0.0001)$. The differences in other cost components between the groups were small, although there was substantial uncertainty around these differences (as is evident from the large SEs). Total costs were $£ 17945$ (SE 332) in the restrictive group and £18 127 (SE 357) in the liberal group, resulting in a mean difference between the groups of $-£ 182$ (SE 488; table 2). This difference in cost was largely associated with the higher cost of red blood cells in the liberal group.

\section{HRQoL and QALYs}

There was very little difference in EQ-5D scores between the trial groups at any of the three time points (table 3). On average, participants' EQ-5D scores did not quite return to their preoperative level by 3 months in either treatment group. QALYs to 3 months were 0.180 for both the restrictive and liberal groups, with a mean difference of only 0.0004 (SE 0.0021 ; table 3 ). This difference of 0.0004 QALYs is 23.5 quality-adjusted hours. Although there was a significant difference in deaths between the groups in favour of the liberal group, this did not translate into a difference in QALYs between the groups. Exploratory plots of the QALY data for survivors and non-survivors at 3 months revealed that it was not just participants who died who had low QALYs, but also many other participants, hence the difference in deaths did not have a major impact on the quality-of-life results.

\section{Cost-effectiveness}

When we considered the point estimate (the initial mean estimate), the restrictive threshold is considered cost-effective: the restrictive threshold is dominant over the liberal threshold, since it is both more effective and less costly (table 4). However, there is great uncertainty around this result, as shown on the cost-effectiveness plane in figure 1. The differences in costs and QALYs between the groups are incredibly small, and therefore the point estimate (the black dot) is close to the origin. The bootstrap replicates of the cost and QALY differences cover all four quadrants of the cost-effectiveness plane, which illustrates that there is actually very little difference between the two groups along with much uncertainty. There is a $43 \%$ probability that the restrictive threshold dominates the liberal threshold, but also a $20 \%$ probability of the reverse scenario, that the liberal threshold dominates the restrictive threshold. In reality, there is no difference in QALYs between the groups, the $95 \%$ CI suggests the maximum difference is less than \pm 2 days.

\section{Sensitivity analyses}

Sensitivity analyses (see online supplementary appendix 3) demonstrated that the conclusions were sensitive to a few very high-cost participants, but robust to changes in unit costs, to moving the time origin from surgery to the time of randomisation, to alternative assumptions for calculating QALYs, and to using life-years instead of QALYs as an alternative outcome measure.

The distribution of total costs per participant was positively skewed for both groups. This skewness was enhanced by the existence of a few very high-cost outliers, especially in the liberal group. Four participants, all in the liberal group, had costs over $£ 100000$ (£101 173; £107 163; £108 865 and £144 985, compared to the average costs of $£ 18127)$. These participants did not have unexpected events; rather, they had large numbers of expected complications and stayed in hospital with a high level of care for some time. Therefore, there were no grounds for excluding these participants from our analyses. Nevertheless, it is instructive to investigate the impact they are having on results since the imbalance across groups of these outliers could easily have arisen by chance. If the participant with the highest cost is excluded, the difference in costs between the groups reduces from $-£ 182$ to $-£ 55$ (smaller than the cost of the average difference in red blood cell use). If participants with the four highest costs are excluded, the liberal group becomes less expensive than the restrictive group, and the difference in costs between the groups changes from $-£ 182$ to $+£ 208$. It is clear that these four participants exerted a significant impact on the average costs of participants in the liberal group.

\section{Subgroup analyses}

There was evidence of only one subgroup effect: participants in the restrictive group with chronic pulmonary disease or asthma had slightly less QALYs compared to other participants $(p=0.003)$. See online supplementary appendix 4 for more details.

\section{DISCUSSION}

There was very little difference between the alternative transfusion groups in either costs or effects, and great uncertainty around the cost-effectiveness results. When a breakdown of total costs was considered, there was a clear difference in the costs associated with red blood cells between the two groups as expected, because the liberal group was given more red blood cells by definition; otherwise, cost components were very similar. The differences in costs between groups were about the same 
Table 1 Resource use per participant to 3 months from surgery

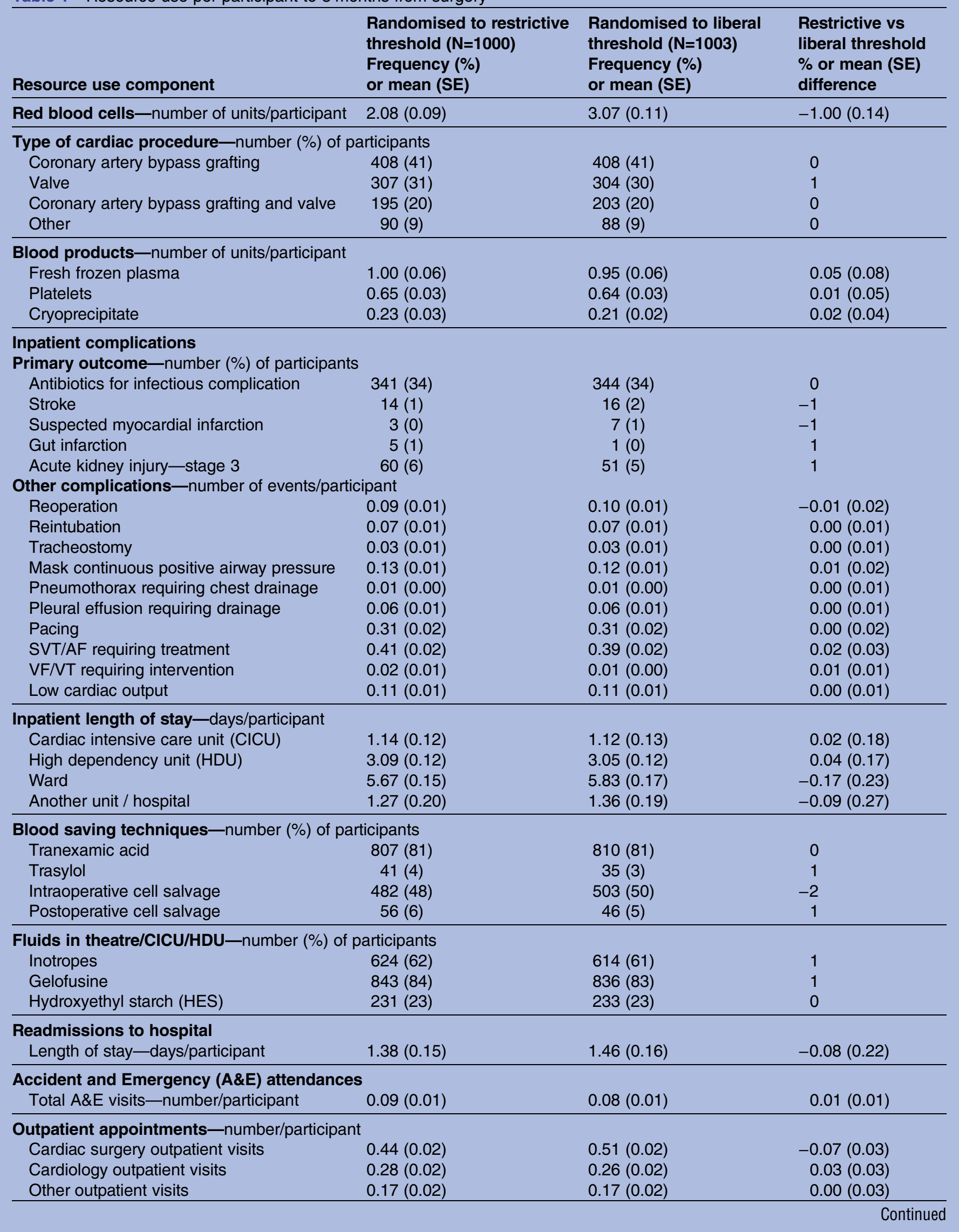


Table 1 Continued

\begin{tabular}{|c|c|c|c|}
\hline Resource use component & $\begin{array}{l}\text { Randomised to restrictive } \\
\text { threshold }(\mathrm{N}=1000) \\
\text { Frequency }(\%) \\
\text { or mean }(\mathrm{SE})\end{array}$ & $\begin{array}{l}\text { Randomised to liberal } \\
\text { threshold }(\mathrm{N}=1003) \\
\text { Frequency }(\%) \\
\text { or mean (SE) }\end{array}$ & $\begin{array}{l}\text { Restrictive vs } \\
\text { liberal threshold } \\
\% \text { or mean (SE) } \\
\text { difference }\end{array}$ \\
\hline \multicolumn{4}{|c|}{ Other healthcare contacts-number/participant } \\
\hline General practitioner at surgery & $1.99(0.06)$ & $2.07(0.07)$ & $-0.09(0.10)$ \\
\hline General practitioner at home & $0.43(0.04)$ & $0.37(0.03)$ & $0.06(0.06)$ \\
\hline Practice nurse & $1.56(0.13)$ & $1.57(0.14)$ & $-0.01(0.19)$ \\
\hline District nurse & $2.47(0.20)$ & $2.21(0.23)$ & $0.26(0.30)$ \\
\hline
\end{tabular}

SVT/AF, supraventricular tachycardia/atrial fibrillation; VF/VT, ventricular fibrillation/ventricular tachycardia.

Table 2 Breakdown of total average cost per participant for both trial groups

\begin{tabular}{|c|c|c|c|}
\hline Cost component & $\begin{array}{l}\text { Randomised to restrictive } \\
\text { threshold }(\mathrm{N}=1000) \\
\text { Mean cost }(\Sigma)(\mathrm{SE})\end{array}$ & $\begin{array}{l}\text { Randomised to liberal } \\
\text { threshold }(N=1003) \\
\text { Mean cost }(£)(S E)\end{array}$ & $\begin{array}{l}\text { Restrictive vs liberal } \\
\text { threshold } \\
\text { Mean cost }(£) \\
\text { difference (SE) }\end{array}$ \\
\hline Red blood cells & $287(13)$ & 427 (15) & $-140(19)$ \\
\hline \multicolumn{4}{|l|}{ Hospital inpatient episode } \\
\hline Initial cardiac surgery & 7309 (18) & $7313(18)$ & $-4(26)$ \\
\hline Other blood products & $206(12)$ & $199(11)$ & $7(16)$ \\
\hline $\begin{array}{l}\text { Complications and serious } \\
\text { adverse events }\end{array}$ & 2684 (137) & 2714 (146) & $-30(200)$ \\
\hline Length of hospital stay* & $5854(201)$ & $5892(221)$ & $-38(299)$ \\
\hline Blood saving techniques & $159(9)$ & $152(8)$ & 7 (12) \\
\hline Regular medications & $26(2)$ & $29(2)$ & $-3(3)$ \\
\hline Fluids & $55(1)$ & $55(1)$ & $0(2)$ \\
\hline Total & $16293(309)$ & 16353 (339) & $-60(459)$ \\
\hline \multicolumn{4}{|l|}{ Postdischarge } \\
\hline Hospital readmissions & $770(85)$ & $753(78)$ & $17(116)$ \\
\hline $\begin{array}{l}\text { Accident and Emergency } \\
\text { visits }\end{array}$ & $16(2)$ & $12(2)$ & $4(3)$ \\
\hline Outpatient appointments & $202(6)$ & $216(7)$ & $-14(9)$ \\
\hline Other medical/social care & $378(14)$ & $366(16)$ & $12(21)$ \\
\hline Total & $1365(90)$ & $1347(82)$ & 18 (122) \\
\hline Total costs & 17945 (332) & $18127(357)$ & $-182(488)$ \\
\hline
\end{tabular}

Table 3 Results for EQ-5D scores and QALYs

\begin{tabular}{lllr}
\hline & $\begin{array}{l}\text { Randomised to restrictive } \\
\text { threshold (N=1000) } \\
\text { Mean (SE) }\end{array}$ & $\begin{array}{l}\text { Randomised to liberal } \\
\text { threshold (N=1003) } \\
\text { Mean (SE) }\end{array}$ & \multicolumn{1}{|l}{$\begin{array}{l}\text { Restrictive vs liberal } \\
\text { threshold } \\
\text { Mean difference (SE) }\end{array}$} \\
\hline EQ-5D time point* & $0.765(0.008)$ & $0.767(0.007)$ & $-0.001(0.011)$ \\
$\quad$ Baseline & $0.692(0.008)$ & $0.686(0.008)$ & $0.006(0.011)$ \\
6 weeks & $0.748(0.009)$ & $0.750(0.008)$ & $-0.002(0.012)$ \\
\hline months & $0.1802(0.0015)$ & $0.1798(0.0016)$ & $0.0004(0.0021)$ \\
\hline $\begin{array}{l}\text { QALYs to 3 months (adjusted } \\
\text { for baseline EQ-5D) }\end{array}$ & & & \\
\hline "Deaths included as zero. & & & \\
QALY, quality-adjusted life year. & & &
\end{tabular}


Table 4 Base case cost-effectiveness results

\begin{tabular}{|c|c|c|c|c|c|c|c|c|c|}
\hline \multicolumn{3}{|c|}{ Total costs $(95 \% \mathrm{Cl})$} & \multicolumn{3}{|c|}{ QALYs (95\% CI) } & \multirow{2}{*}{$\begin{array}{l}\text { ICER } \\
\text { Cost/QALY }\end{array}$} & \multicolumn{3}{|c|}{$\begin{array}{l}\text { Probability restrictive is } \\
\text { cost-effective at a ceiling } \\
\text { ratio of }\end{array}$} \\
\hline $\begin{array}{l}\text { Restrictive } \\
\text { threshold } \\
(\mathrm{N}=1000)\end{array}$ & $\begin{array}{l}\text { Liberal } \\
\text { threshold } \\
(\mathrm{N}=1003)\end{array}$ & $\begin{array}{l}\text { Restrictive } \\
\text { vs liberal } \\
\text { threshold }\end{array}$ & $\begin{array}{l}\text { Restrictive } \\
\text { threshold } \\
(\mathrm{N}=1000)\end{array}$ & $\begin{array}{l}\text { Liberal } \\
\text { threshold } \\
(\mathrm{N}=1003)\end{array}$ & $\begin{array}{l}\text { Restrictive } \\
\text { vs liberal } \\
\text { threshold }\end{array}$ & & $£ 20000$ & $£ 50000$ & $£ 100000$ \\
\hline $\begin{array}{l}£ 17945 \\
(£ 17273 \text { to } \\
£ 18618)\end{array}$ & $\begin{array}{l}£ 18127 \\
(£ 17450 \\
\text { to } \\
£ 18804)\end{array}$ & $\begin{array}{l}-£ 182 \\
(-£ 1108 \\
\text { to } £ 744)\end{array}$ & $\begin{array}{l}0.1802 \\
(0.1772 \text { to } \\
0.1832)\end{array}$ & $\begin{array}{l}0.1798 \\
(0.1766 \text { to } \\
0.1829)\end{array}$ & $\begin{array}{l}0.0004 \\
(-0.0037 \text { to } \\
0.0045)\end{array}$ & $\begin{array}{l}\text { Restrictive } \\
\text { dominant } \\
(-£ 428 \\
064)\end{array}$ & $65 \%$ & $66 \%$ & $66 \%$ \\
\hline
\end{tabular}

when considering only the red blood cell costs and when considering all costs; however, the former difference was estimated more precisely than the latter. Mean QALYs to 3 months were effectively identical in both groups. The point estimate of cost-effectiveness suggested that the restrictive group was more effective (very slightly greater QALY gain) and less costly than the liberal group (ie, dominant), and therefore costeffective. However, the extreme uncertainty around this result makes the point estimate less informative. The uncertainty is shown on the cost-effectiveness plane by the position of the point estimate close to the origin, and by the fact that the bootstrap replicates of the cost and QALY differences covered all four quadrants of the plane. Moreover, there were several outliers in the liberal group which exerted a substantial influence on the average costs of participants in that treatment group, reversing the direction of the results described above when they were excluded.

Our economic evaluation had several key strengths. It was based on high-quality cost and quality of life individual patient data collected in a randomised trial. Very detailed data collection was undertaken, and the trial achieved

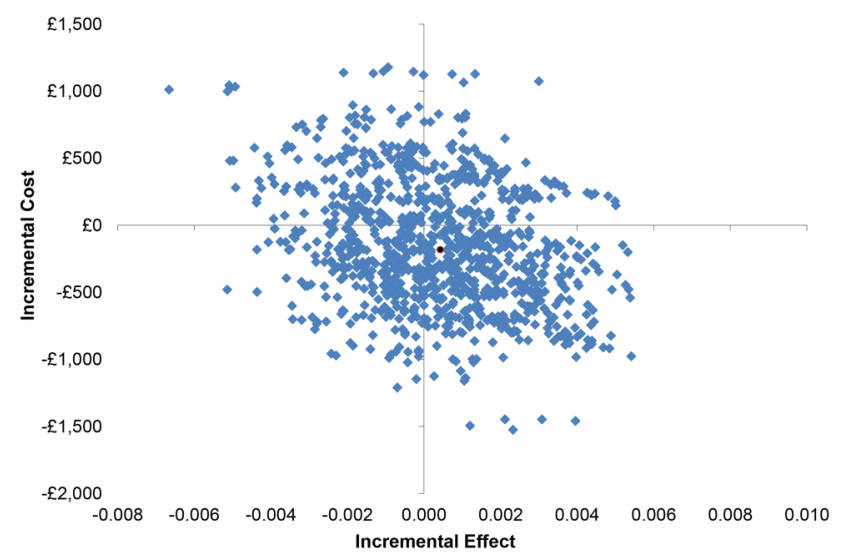

Figure 1 Cost-effectiveness plane. In order that the points could be seen, only 1000 replicates were plotted (200 replicates for each of the five imputations). excellent completeness of follow-up (follow-up at 3 months postrandomisation was obtained for $98.7 \%$ of participants). TITRe2 was a large trial, randomising four times more participants than the next largest trial comparing restrictive and liberal transfusion thresholds after cardiac surgery. In TITRe2, only participants who breached the liberal threshold were randomised; this avoided diluting the treatment effect with similar numbers of participants in each group who were unlikely to be transfused. Costs and cost-effectiveness estimates were similarly not diluted by patients who were unlikely to be transfused. There is one limitation to note around the unit costs of administering blood products. The unit costs of administering red blood cells used in this study captured the nursing costs associated with transfusion (based on UK data), but not other inputs such as those of the transfusion laboratory; and no costs associated with administration were included for other blood products. Unit costs for blood administration used here were much lower than those reported elsewhere. ${ }^{23-25}$ Given there was only a difference of one unit of red blood cells between the transfusion groups, (and a very small difference in total costs), it is unlikely that the inclusion of additional blood administration costs would alter the conclusions.

To the best of our knowledge, this is the first trial-based economic evaluation assessing the costeffectiveness of alternative transfusion thresholds after cardiac surgery. A Cochrane systematic review of randomised controlled trials (RCTs) comparing restrictive and liberal transfusion thresholds in surgical patients and the critically ill was published in 2012. ${ }^{26}$ None of the RCTs included in the review, nor five additional trials published subsequently, included an integral economic evaluation, ${ }^{27-31}$ (one pilot trial included an exploratory economic evaluation, but the only inpatient resource captured was LOS by level of care)..$^{31}$

Although the TITRe2 trial was a well-designed and rigorously conducted trial, the interpretation of its costeffectiveness results is challenging because the differences in costs and quality of life between the groups were small or uncertain (across both the clinical and 
cost-effectiveness analyses). Point estimates of costeffectiveness (based on QALYs as the primary health economic outcome measure or life years in a sensitivity analysis) suggested that a restrictive threshold was costeffective, but there was extreme uncertainty around these results. From an economic perspective, we conclude that there is no difference between the restrictive and liberal groups. While there was no difference in the primary clinical outcome, there was a borderline difference in mortality between the groups, favouring a liberal threshold. It is difficult to recommend restrictive transfusion after cardiac surgery, given that more patients died in the restrictive group. While there is a growing body of evidence that restrictive transfusion thresholds are safe for most patient groups, ${ }^{32}$ there is recognition that patients with acute or chronic cardiovascular disease, may benefit from more liberal transfusion. ${ }^{33} 34$

A difference of $\sim £ 200$ between the groups is a modest cost difference ( $\sim 1 \%$ of total costs). However, since 34174 cardiac surgery procedures were undertaken in the UK in $2012 / 2013,{ }^{35}$ a difference of $£ 200$ in each procedure would have resulted in savings or additional costs of $£ 6.8$ million for the NHS. The effect of this cost difference, and whether it is a cost saving or additional cost, is clearly important for the NHS. If there is a saving of £200 per patient, and this is largely attributable to savings in the cost of blood, this would substantially reduce the amount paid to NHSBT for blood products. These savings could be used to support Patient Blood Management (PBM) initiatives, to optimise care for patients who might need a transfusion. A recent audit of PBM in surgery highlighted considerable variation in practice, and the need for hospitals to develop single-unit transfusion policies with clearly defined transfusion triggers. ${ }^{36}$

In summary, our findings suggest that there is no health economic evidence to suggest a difference between the two alternative blood transfusion thresholds, as there was very little difference between the alternative transfusion groups in either costs or effects, but great uncertainty around the cost-effectiveness results.

\section{Author affiliations}

${ }^{1}$ Nuffield Department of Population Health, Health Economics Research Centre, University of Oxford, Oxford, UK

${ }^{2}$ Eli Lilly and Company Limited, Lilly House, Basingstoke, Hampshire, UK ${ }^{3}$ Clinical Trials and Evaluation Unit, School of Clinical Sciences, University of Bristol, Bristol, UK

${ }^{4}$ Bristol Heart Institute, School of Clinical Sciences, University of Bristol, Bristol, UK

${ }^{5}$ Department of Cardiovascular Sciences and NIHR Leicester Biomedical Research Unit in Cardiovascular Medicine, University of Leicester, Leicester, UK

Acknowledgements The authors thank all the patients who took part in the TITRe2 trial, and all the nurses and clinicians in the trial centres who helped to collect data on costs and patient outcomes which were used in the cost-effectiveness analysis.

Collaborators Transfusion Indication Threshold Reduction study investigators and trial sites. Blackpool Victoria Hospital and Lancaster University. Investigators: Mr Augustine Tang and Dr Palaniappan Saravanan. Research team: Charlotte Waterhouse. Royal Sussex County Hospital, Brighton. Investigator: Dr Robert
Kong. Research team: Nicola Skipper. University Hospitals NHS Foundation Trust, Bristol. Investigator: Professor Gavin Murphy (until August 2012)/ Professor Gianni Angelini (from August 2012). Research team: Emma Hopkins and Penny Lambert. University Hospital Coventry and Warwickshire NHS Trust, Coventry. Investigator: Mr Sunil K Bhudia. Research team: Denise Gocher. Castle Hill Hospital, Hull. Investigator: Dr Sean Bennett. Research team: Neil Smith and Adam Walker. Derriford Hospital, Plymouth. Investigators: Dr Mark Bennett and Mr Malcolm Dalrymple-Hay. Research team: Maxine Pearse. Essex Cardiothoracic Centre, Basildon. Investigator: Professor Andrew J Ritchie. Research team: Emily Redman and Amanda Solesbury. Royal Infirmary of Edinburgh, Edinburgh. Investigator: Mr Vipin Zamvar. Hammersmith Hospital, London. Investigator: Dr Geoffrey Lockwood. Research team: Dr Francesca Fiorentino and Alima Rahman. King's College Hospital NHS Foundation Trust. Investigator: Dr Gudrun Kunst. Research team: Georgina Parsons and Fiona Wade-Smith. The Leeds Teaching Hospitals NHS Trust. Investigator: Dr Michae H Cross. Research team: Stuart Elliot and Zoe Beardow. Glenfield Hospital, Leicester. Investigator: Professor Tom Sypt. Research team: Martina Williams. Liverpool Heart and Chest Hospital Foundation Trust. Investigator: Mr Brian Fabri (until December 2012)/Mr Mark Field (from January 2013). Research team: Ian Kemp and Andrea Young. The James Cook University Hospital, Middlesbrough. Investigator: Dr Nick Stratford. Research team: Heather Robinson. Freeman Hospital, Newcastle. Investigator: Mr Stephen Clark. Research team: Sarah Rowling and Hazel Forsyth. University Hospital Southampton Foundation Trust. Investigator: Dr Ravi Gill. Research team: Beverley Wadhams and Kim de Courcy-Golder. New Cross Hospital, Wolverhampton. Investigator: Dr lan Morgan. Research team: Emma Greatbach and Alex Ng.

Contributors GJM, BCR, GDA and CAR conceived the trial. GJM, BCR, GDA, CAR and SW wrote the application for funding to conduct the trial. GJM, $\mathrm{BCR}, \mathrm{GDA}$ and CAR designed the trial. KP, BCR and CAR designed the trial data set and collected the outcome data which were used for the economic evaluation. EAS and SW conceived and designed the health economic evaluation. EAS conducted the economic analysis with help from SW and DB. EAS and SW drafted the paper. All authors participated in writing the paper, reviewed it for important intellectual content and approved the final version.

Funding This project was funded by the National Institute for Health Research (NIHR) Health Technology Assessment (HTA) Programme (ref: 06/402/94). $\mathrm{BCR}$ and the research nurse team in Bristol were supported, in part, by the NIHR Bristol Biomedical Research Unit in Cardiovascular Disease, and GJM, GDA and CAR were supported by the British Heart Foundation (ref: $\mathrm{CH} / 12 / 1$ / 29419 and $\mathrm{CH} / 92027)$. DB was working full-time at the Health Economics Research Centre, University of Oxford at the time of the cost-effectiveness work and moved to Eli Lilly at a later date. The study funder had no role in the cost-effectiveness study design, data collection, data analysis, data interpretation, or writing of the paper. EAS and SW had full access to all the data in the study, and the authors had final responsibility for the decision to submit for publication. The views and opinions expressed herein are those of the authors and do not necessarily reflect those of the HTA programme, the British Heart Foundation, NIHR, NHS or the Department of Health.

Competing interests RCMB, GJM (up to 31 Aug 2012), KP, SW, EAS, DB and $B C R$ had varying percentages of their salaries paid for by the grant awarded for the trial. Some or all of the time contributed by GDA, GJM (from 1 Sep 2012) and CAR was paid for by the British Heart Foundation. CAR is a member of the NIHR Health Technology Assessment Commissioning Board, Systematic Reviews Programme Advisory Board and the Efficient Studies Design Board.

Ethics approval The trial was approved by a UK NHS Research Ethics Committee (reference number 08/H0606/125) and conducted in accordance with the principles of the International Conference on Harmonisation of Good Clinical Practice under the oversight of the study sponsor (University of Bristol).

Provenance and peer review Not commissioned; externally peer reviewed.

Data sharing statement Extra data on the costing information used for our analysis will be available by emailing sarah.wordsworth@dph.ox.ac.uk. Data will not be made available for sharing until after publication of the main Health Technology Assessment Report and the cost-effectiveness analysis paper. Thereafter, anonymised individual participant data may be made available for secondary research, conditional on assurance from the secondary researcher that the proposed use of the data is compliant with the 
MRC Policy on Data Preservation and Sharing regarding scientific quality, ethical requirements and value for money. A minimum requirement with respect to scientific quality will be a publicly available prespecified protocol describing the purpose, methods and analysis of the secondary research, for example, a protocol for a Cochrane systematic review.

Open Access This is an Open Access article distributed in accordance with the terms of the Creative Commons Attribution (CC BY 4.0) license, which permits others to distribute, remix, adapt and build upon this work, for commercial use, provided the original work is properly cited. See: http:// creativecommons.org/licenses/by/4.0/

\section{REFERENCES}

1. Habib RH, Zacharias A, Schwann TA, et al. Role of hemodilutional anemia and transfusion during cardiopulmonary bypass in renal injury after coronary revascularization: implications on operative outcome. Crit Care Med 2005;33:1749-56.

2. Murphy GJ, Reeves BC, Rogers CA, et al. Increased mortality, postoperative morbidity, and cost after red blood cell transfusion in patients having cardiac surgery. Circulation 2007;116:2544-52.

3. Karkouti K, Wijeysundera DN, Beattie WS, et al. Risk associated with preoperative anemia in cardiac surgery: a multicenter cohort study. Circulation 2008;117:478-84.

4. Bennett-Guerrero E, Zhao Y, O'Brien SM, et al. Variation in use of blood transfusion in coronary artery bypass graft surgery. JAMA 2010;304:1568-75.

5. Murphy MF, Murphy GJ, Gill R, et al. National Comparative Audit of Blood Transfusion: 2011 Audit of Blood Transfusion in Adult Cardiac Surgery. 2013. http://hospital.blood.co.uk/media/26859/nca-2011 use of_blood_in_adult_cardiac_surgery_report.pdf (accessed 30 Jul 2015).

6. Wells AW, Llewelyn CA, Casbard A, et al. The EASTR Study: indications for transfusion and estimates of transfusion recipient numbers in hospitals supplied by The National Blood Service. Transfus Med 2009;19:315-28.

7. Brierley RCM, Pike K, Miles A, et al. A multi-centre randomised controlled trial of Transfusion Indication Threshold Reduction on transfusion rates, morbidity and healthcare resource use following cardiac surgery: study protocol. Transfus Apher Sci 2014;50:451-61.

8. Corwin HL, Parsonnet KC, Gettinger A. RBC transfusion in the ICU. Is there a reason? Chest 1995;108:767-71.

9. Stover EP, Siegel LC, Parks R, et al. Variability in transfusion practice for coronary artery bypass surgery persists despite national consensus guidelines: a 24-institution study. Institutions of the Multicenter Study of Perioperative Ischemia Research Group. Anesthesiology 1998;88:327-33.

10. Murphy GJ, Pike K, Rogers CA, et al. Liberal or restrictive transfusion after cardiac surgery. N Engl J Med 2015;372: 997-1008.

11. National Institute for Health and Care Excellence. Guide to the Methods of Technology Appraisal 2013. 2013. https://www.nice.org. uk/article/pmg9/resources/non-guidance-guide-to-the-methods-oftechnology-appraisal-2013-pdf (accessed 30 Jul 2015).

12. Department of Health. National Schedule of Reference Costs 2012 13. London: Department of Health, 2013.

13. NHS Blood and Transplant. NHS Blood and Transplant Price List 2012-2013. 2012. http://hospital.blood.co.uk/products/ (accessed 28 Sep 2012).

14. Curtis L. Unit costs of health and social care 2013. Canterbury: Personal Social Services Research Unit, University of Kent, 2013.

15. Department of Health Commercial Medicines Unit. Electronic Marketing Information Tool (eMIT). Drugs and Pharmaceutical
Electronic Market Information (eMit). http://cmu.dh.gov.uk/ electronic-market-information-tool-emit/ (accessed $10 \mathrm{Feb}$ 2014).

16. Joint Formulary Committee. British national formulary. No. 66 . London: BMJ Group and Pharmaceutical Press, 2013.

17. Dolan P, Gudex C, Kind P, et al. A social tariff for euroqol: results from a UK general population survey. University of York, 1995.

18. White IR, Royston P, Wood AM. Multiple imputation using chained equations: issues and guidance for practice. Stat Med 2011;30:377-99.

19. Rubin DB. Multiple Imputation for non-response in surveys. New York: John Wiley, 1987.

20. Manca A, Hawkins N, Sculpher MJ. Estimating mean QALYs in trial-based cost-effectiveness analysis: the importance of controlling for baseline utility. Health Econ 2005;14:487-96.

21. Briggs $\mathrm{AH}$, Wonderling DE, Mooney CZ. Pulling cost-effectiveness analysis up by its bootstraps: a non-parametric approach to confidence interval estimation. Health Econ 1997;6:327-40.

22. Briggs A, Clark T, Wolstenholme J, et al. Missing... presumed at random: cost-analysis of incomplete data. Health Econ 2003;12:377-92.

23. Shander A, Hofmann A, Ozawa S, et al. Activity-based costs of blood transfusions in surgical patients at four hospitals. Transfusion 2010:50:753-65.

24. Shander A, Ozawa S, Hofmann A. Activity-based costs of plasma transfusions in medical and surgical inpatients at a US hospital. Vox Sang 2016;111:55-61.

25. Abraham I, Sun D. The cost of blood transfusion in Western Europe as estimated from six studies. Transfusion 2012;52:1983-8.

26. Carson JL, Carless PA, Hebert PC. Transfusion thresholds and other strategies for guiding allogeneic red blood cell transfusion. Cochrane Database Syst Rev 2012;(4):CD002042.

27. Carson JL, Terrin ML, Noveck $\mathrm{H}$, et al. Liberal or restrictive transfusion in high-risk patients after hip surgery. N Engl $J$ Med 2011;365:2453-62.

28. Shehata N, Burns LA, Nathan $\mathrm{H}$, et al. A randomized controlled pilot study of adherence to transfusion strategies in cardiac surgery. Transfusion 2012;52:91-9.

29. Carson JL, Brooks MM, Abbott JD, et al. Liberal versus restrictive transfusion thresholds for patients with symptomatic coronary artery disease. Am Heart J 2013;165:964-71.e1.

30. Villanueva C, Colomo A, Bosch A, et al. Transfusion strategies for acute upper gastrointestinal bleeding. N Engl J Med 2013;368:11-21.

31. Walsh TS, Boyd JA, Watson D, et al. Restrictive versus liberal transfusion strategies for older mechanically ventilated critically ill patients: a randomized pilot trial. Crit Care Med 2013;41:2354-63.

32. Holst LB, Petersen MW, Haase N, et al. Restrictive versus liberal transfusion strategy for red blood cell transfusion: systematic review of randomised trials with meta-analysis and trial sequential analysis. BMJ 2015;350:h1354

33. Docherty AB, O'Donnell R, Brunskill S, et al. Effect of restrictive versus liberal transfusion strategies on outcomes in patients with cardiovascular disease in a non-cardiac surgery setting: systematic review and meta-analysis. BMJ 2016;352:11351.

34. Patel NN, Avlonitis VS, Jones HE, et al. Indications for red blood cell transfusion in cardiac surgery: a systematic review and meta-analysis. Lancet Haematol 2015;2:e543-53.

35. The Society for Cardiothoracic Surgery in Great Britain \& Ireland Blue Book Online. 2013. http://bluebook.scts.org

36. NHS Blood and Transplant. 2015 Audit of Patient Blood Management in adults undergoing elective, scheduled surgery. 2016. http://hospital.blood.co.uk/audits/national-comparative-audit/ (accessed 20 Apr 2016). 